\title{
Meta-Analysis of the Association of HLA-DRB1 with Anti-Citrullinated Protein Antibody-Positive and Anti-Citrullinated Protein Antibody-Negative Rheumatoid Arthritis
}

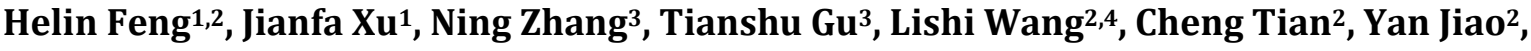 \\ Karen Hasty ${ }^{2}$, Weikuan Gu${ }^{2 *}$, Qingyi Liu ${ }^{*}$ \\ ${ }^{1}$ Department of Orthopedics, The Fourth Hospital of Hebei Medical University, Shijiazhuang, China \\ ${ }^{2}$ Department of Orthopedic Surgery and BME, University of Tennessee Health Science Center, Memphis, TN, USA \\ ${ }^{3}$ Department of Cardiology, The Fourth Hospital of Hebei Medical University, Shijiazhuang, China \\ ${ }^{4}$ Department of Basic Research, Inner Mongolia Medical University, Inner Mongolia, China \\ Email: *zhongmeijian-lqy@163.com
}

How to cite this paper: Feng, H.L., Xu, J.F., Zhang, N., Gu, T.S., Wang, L.S., Tian, C., Jiao, Y., Hasty, K., Gu, W.K. and Liu, Q.Y. (2016) Meta-Analysis of the Association of HLA-DRB1 with Anti-Citrullinated Protein Antibody-Positive and Anti-Citrullinated Protein Antibody-Negative Rheumatoid Arthritis. Open Journal of Immunology, 6, 121-135.

http://dx.doi.org/10.4236/oji.2016.64013

Received: October 22, 2016

Accepted: November 21, 2016

Published: November 24, 2016

Copyright $\odot 2016$ by authors and Scientific Research Publishing Inc. This work is licensed under the Creative Commons Attribution International License (CC BY 4.0).

http://creativecommons.org/licenses/by/4.0/ (c) $\underset{\mathrm{EY}}{\text { (†) Open Access }}$

\section{Abstract}

Because of genetic complex and variations of auto antibodies of rheumatoid arthritis (RA) in different populations, the data on the association of HLA-DRB1 alleles in anti-citrullinated protein antibody of (ACPA) RA were inconsistent. The purpose of the study is to systematically summarize results of published data through performing a meta-analysis using data in which HLA-DRB1 alleles are associated with ACPApositive RA and ACPA-negative RA. In this study, we collected data from 12 studies with 13,861 cases and 12,896 controls. Information in these studies included HLADRB1 typing and ACPA status from different countries. Odds ratios (ORs) and corresponding 95\% confidence intervals (CI) were used to analyze the association of different HLA-DRB1 alleles with ACPA-positive RA or ACPA-negative RA. To correct skewing data, the analysis of ACPA-status was stratified by patient distribution. Our analyses indicate that in ACPA-positive RA, all patients with RA had significantly higher frequencies of HLA-DRB $1{ }^{\star} 01,{ }^{\star} 04,{ }^{\star} 0401,{ }^{\star} 0405,{ }^{\star} 07,{ }^{\star} 11,{ }^{\star} 13$ and ${ }^{\star} 14$ than controls. One of the HLA-DRB1 ${ }^{\star} 07,{ }^{\star} 11,{ }^{\star} 13$ and ${ }^{\star} 14$ showed protective association with RA. In addition, HLA-DRB ${ }^{\star} 03,{ }^{\star} 10$ and ${ }^{\star} 12$ had more influence than control to RA in European populations; the HLA-DRB1*03 and ${ }^{\star} 12$ alleles were associated with the protection. In ACPA-negative RA, only $\mathrm{DRB1}{ }^{\star} 07$ was associated with the protection (OR 0.53 [95\% CI 0.36 - 0.76]) among all HLA-DRB1 alleles in European populations. In ACPA-positive RA, currently available results indicate that ${ }^{\star} 01,{ }^{\star} 04,{ }^{\star} 0401$ and ${ }^{\star} 0405$ are susceptible, while HLA-DRB $1{ }^{\star} 07,{ }^{\star} 11,{ }^{\star} 13$ and ${ }^{\star} 14$ are 
protective in all populations. While the HLA-DRB1 ${ }^{\star} 10$ is susceptible, HLA-DRB1 $1^{\star} 03$ and ${ }^{\star} 12$ show protective association with RA in European populations. Additionally, regardless of the positive or negative ACPA, the $\mathrm{DRB} 1{ }^{\star} 07$ is always associated with protection in European populations.

\section{Keywords}

Alleles, Anti-Citrullinated Protein Antibody, Hla-Drb1, Populations, Rheumatoid Arthritis

\section{Introduction}

Rheumatoid arthritis (RA) is an autoimmune and worldwide prevalent disease that is characterized by the symmetric joint destruction and disability [1]. The prevalence of RA in the patients living in variety of areas is presumably associated with the complex interaction between specific environmental conditions of geographical areas and the polymorphism of the immune response genes in the population [2]. Human Leukocyte Antigen (HLA) alleles, especially the HLADRB1*04, HLADRB $1^{\star} 01$ and HLA-DRB1*10, are strongly associated with RA [3] [4]. Based on the fact that the shared epitope (SE) is located in positions of 70 - 74 (QKRAA, RRRAA, or QRRAA) of the HLA-DRB1 chain, the hypothesis that the SE HLA-DRB1 alleles were associated with developing RA was generated [5] [6]. The hypothesis provides the theoretical basis of further investigating the effects of the HLA alleles to the RA [7] [8]. Because of the complexity of the HLA region, not all HLA SE alleles carried susceptibility for RA [9].

The study of anti-citrullinated peptide antibodies (ACPA) revealed that the HLA SE alleles were strongly associated with the ACPA response [10]. Furthermore, the DRB1* 13:02 was discovered to play the protective role of ACPA-positive RA in Japanese. However, in ACPA-negative RA the study showed a negative association of DRB1*13:02 with Japanese RA [11]. The different results indicated the different ACPA-status probably constituted distinct patient population with different underlying pathogenetic backgrounds.

The multitude of classifications HLA alleles indicated that the predisposing and protective effects of HLA alleles in RA seemed to be straightforward. However, due to the use of different classifications by geographic regions or ACPA-status, the results of the effects of HLA alleles can be conflicted.

The meta-analysis was performed to overcome the problems of small sample size and conflicted results according to achieved data. Several meta-analyses have indicated the strong association between HLA-DRB1 and RA in different population, for example, DRB1 ${ }^{\star} 04: 01$ and ${ }^{\star} 04: 05$ were close associated with RA in European and East Asian populations [12] [13]. However, it is not clear whether classifications based on ACPApositive or ACPA-negative data from different geographic areas have similar results. 


\section{Materials and Methods}

\subsection{Literature Search and Selection}

We searched Cochrane Library, Pubmed and EMB ASE databases of available articles of English language using the index terms "human leukocyte antigen DRB1" or "HLADRB1" and "rheumatoid arthritis" or "RA" or "rheumatoid joints" or "polyarthritis destruens", from inception to 30 June, 2015. In order to not miss any eligible articles, we cross-searched references of included articles. The search strategy follows the "Preferred Reporting Items for Systematic Reviews and Meta-Analyses statement”.

\subsection{Inclusion Criteria}

The following criteria were used to determine the eligible articles for meta-analysis: 1) the diagnosis of RA patients with standard criteria of American College of Rheumatology (ACR) in 1987 must be included. 2) Study must be associated with HLA-DRB1 and the ACPA-positive RA or ACPA-negative RA. 3) The original data and methods were well-described and reliable. 4) If many articles were from same authors and institutions, the most eligible single article was selected. Review articles are not included.

\subsection{Quality Assessment of Included Studies}

Two reviewers (Helin Feng and Jianfa Xu) independently assessed the quality of articles based on the Newcastle-Ottawa quality assessment scale [14]. Three dimensions, including selection of patients, comparability, and outcome assessment, were focused in the scale. We specified a priori that was denoted by a numerical score ranging from 0 to 9, with 7 or higher representing high quality, 5 or 6 representing moderate quality, 4 or less indicating low quality.

\subsection{Data Extraction}

Two investigators (Helin Feng and Jianfa $\mathrm{Xu}$ ) extracted the following information from each article: the first author's name, the date of publication, geographical region, study design, sample, source of cases and controls, frequency of HLA-DRB1 alleles, number of cases and controls. The geographical populations can be classified into European populations and Asia or African populations. Because of significantly geographic variation in populations, all subjects were divided into Europe or non-Europe origin in the subgroup analysis. Notably, due to small numbers of patients and control subjects from Africa, the date from Asian and African populations grouped together in the analysis. Disagreement was resolved by discussion or revisiting the article until consensus was reached.

\subsection{Statistical Analysis}

The state package version 12.0 (Stata Corporation, College Station, TX, USA) was applied in the meta-analysis. The summary odds ratios (ORs) with $95 \%$ confidence intervals (CIs) were calculated to indicate the association of the different HLA-DRB1 alleles with the development of different ACPA-status RA. The statistical heterogeneity 
among the studies was assessed by a chi-square-based $\mathrm{Q}$ statistic test and the $\mathrm{I}^{2}$ statistic $\left(\mathrm{I}^{2}=0 \%-50 \%\right.$, no or moderate heterogeneity; $\mathrm{I}^{2}>50 \%$, significant heterogeneity) [15] [16]. If the homogeneity was significant $(\mathrm{P}>0.10$ for the $\mathrm{Q}$ test or $\mathrm{I} 2 \%>50 \%$ ), the random-effect model was used. Otherwise, the fixed-effect model was used. The Egger's test and Begg's test were used to assess publication bias [17]. And we applied sensitivity analysis to examine the stability of the pooled results. All $\mathrm{P}$ values were two-sided, and $\mathrm{P}<0.05$ was considered to be statistically significant.

\section{Results}

A total of 305 references were initially identified using keywords as described. 239 articles were excluded from the study after reviewing the titles or abstracts. Thirty three citations were excluded after further evaluation of the ineligible of the articles. In further selection steps, 4 studies were eliminated due to duplicate data and 17 were also excluded because of insufficient data about HLA-DRB1 alleles frequency on cases or controls. As a result, 12 articles [5] [11] [18]-[27] were selected and analyzed. These studies include a total of 13,861 cases and 12,896 controls in the analysis of the association of HLA-DRB1 alleles with ACPA-positive RA and ACPA-negative RA in European, Asia and African patients. Figure 1 shows the selection process for the analysis. The main characteristics of included articles are present in Table 1.

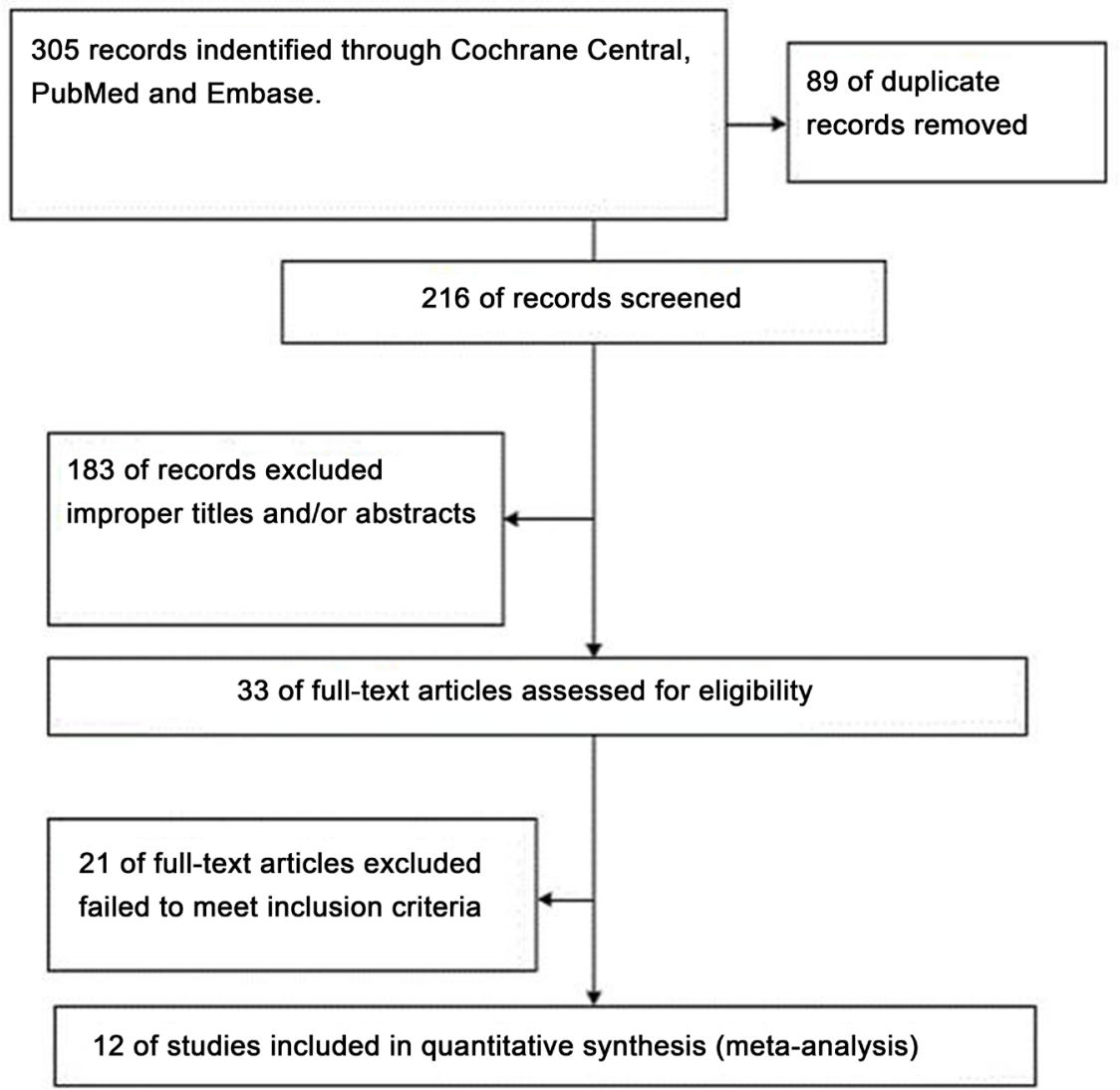

Figure 1. Selection process for the studies included in the meta-analysis. 
Table 1. Main characteristics of the 12 studies included in the final meta-analysis.

\begin{tabular}{|c|c|c|c|c|c|c|c|}
\hline First author & Year & Country & Source of cases & Source of controls & Number of cases & Number of controls & Study quality \\
\hline Prifti-Kurti M & 2014 & Albanian & Hospital-based & Population-based & 100 & 191 & 7 \\
\hline Djidjik R & 2014 & Algeria & Hospital-based & Population-based & 134 & 132 & 9 \\
\hline Shimane K & 2013 & Japan & Hospital-based & Population-based & 2410 & 911 & 8 \\
\hline Balandraud N & 2013 & France & Hospital-based & Population-based & 857 & 2187 & 8 \\
\hline Ucar F & 2012 & Turkey & Hospital-based & Population-based & 291 & 253 & 6 \\
\hline Rheumatology Unit & 2012 & Sweden & Hospital-based & Population-based & 1076 & 1612 & 9 \\
\hline Ben Hamad M & 2012 & Tunisia & Hospital-based & Population-based & 142 & 123 & 8 \\
\hline Ding B & 2009 & Sweden & Hospital-based & Population-based & 1895 & 2389 & 9 \\
\hline
\end{tabular}

\subsection{Associations between HLA-DRB1 Alleles and ACPA-Negative RA}

The results of the meta-analysis for ACPA-negative RA were shown in Table 2. The results indicated possible protective effect of $\mathrm{DRB} 1^{\star} 07, \mathrm{DRB} 1^{\star} 13$ and $\mathrm{DRB} 1^{\star} 1302$, and a predisposing effect of $\mathrm{DRB} 1^{\star} 0405$ on ACPA-negative RA based on without classification in geographical differences. However, correlations of $\mathrm{DRB} 1^{\star} 1302$ and $\mathrm{DRB} 1^{\star} 0405$ with ACPA-negative RA were weakly significant.

To detect the effects of $\mathrm{DRB} 1^{\star} 07, \mathrm{DRB} 1^{\star} 10, \mathrm{DRB} 1^{\star} 12$ and $\mathrm{DRB} 1^{\star} 13$, the subgroup analysis were performed according to geographic differences. The results documented that $\mathrm{DRB} 1^{\star} 10$ and $\mathrm{DRB} 1^{\star} 12$ could play a predisposing effect as well as that $\mathrm{DRB} 1^{\star} 10$ exert a protective effect of ACPA-negative RA in Asia or/and African populations. However, these associations need to be confirmed by further studies.

\subsection{Associations between HLA-DRB1 Alleles and ACPA-Positive RA}

The results of the meta-analysis for ACPA-positive RA are shown in Table 3 . The analysis revealed that $\mathrm{DRB} 1^{\star} 01, \mathrm{DRB}^{\star} 04, \mathrm{DRB} 1^{\star} 0401, \mathrm{DRB} 1^{\star} 0404, \mathrm{DRB} 1^{\star} 0405$ and $\mathrm{DRB} 1^{\star} 10$ played predisposing effects, while $\mathrm{DRB} 1^{\star} 03, \mathrm{DRB} 1^{\star} 0403, \mathrm{DRB} 1^{\star} 0406$, $\mathrm{DRB} 1{ }^{\star} 07, \mathrm{DRB} 1^{\star} 08, \mathrm{DRB} 1^{\star} 11, \mathrm{DRB} 1 * 12, \mathrm{DRB} 1^{\star} 13, \mathrm{DRB} 1^{\star} 1301, \mathrm{DRB} 1{ }^{\star} 1302$, $\mathrm{DRB}^{\star} 14$ and $\mathrm{DRB} 1^{\star} 15$ carried protective effects of ACPA-positive RA based on without classification in geographical differences. It is apparent that the predisposing effects of $\mathrm{DRB} 1^{\star} 01, \mathrm{DRB} 1^{\star} 04, \mathrm{DRB} 1^{\star} 0401$ and $\mathrm{DRB} 1^{\star} 0405$ and the protective effects of $\mathrm{DRB}^{\star} 07, \mathrm{DRB} 1^{\star} 11$ and $\mathrm{DRB} 1^{\star} 13$ were shown in either European RA patients or Asia or/and African RA populations. The predisposing effects of $\mathrm{DRB} 1^{\star} 10$ and protective effects of $\mathrm{DRB} 1^{\star} 03$ and $\mathrm{DRB} 1^{\star} 12$ were observed only in European RA patients. Concomitantly, we also found that the protective effects of $\mathrm{DRB} 1^{\star} 08$ were visible only in Asia or/and African RA populations. However, the evaluation that the $\mathrm{DRB} 1^{\star} 0403$, 
Table 2. HLA-DRB1 associations with ACPA-negative RA according to meta-analysis*.

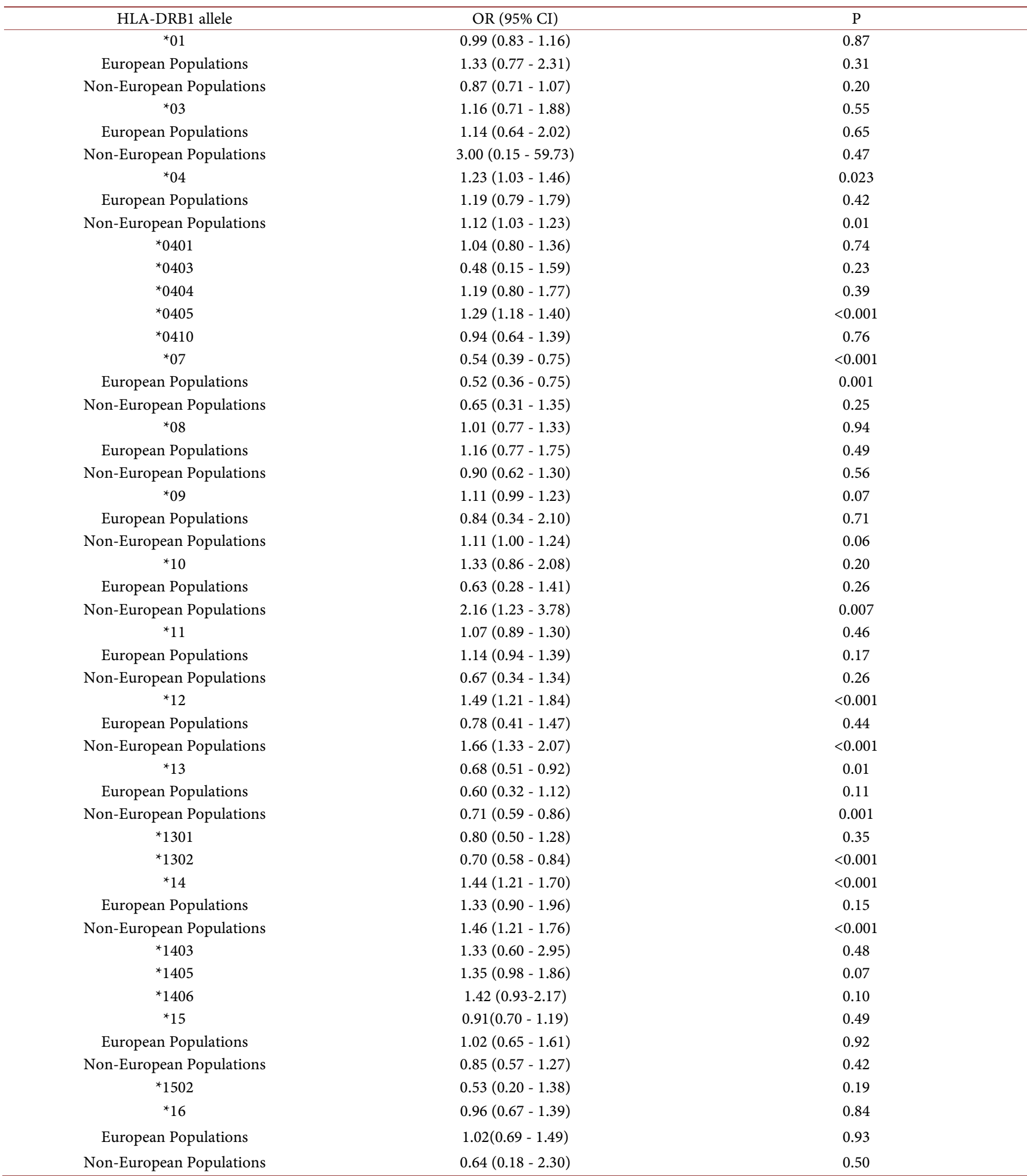

${ }^{*}$ Odds ratios (ORs) depicting a negative association with a $\mathrm{P}$ value of $<0.01$ after stratification were considered to represent a protective effect and are printed in bold; ORs depicting a positive association with a $\mathrm{P}$ value of $<0.01$ after stratification were considered to represent a predisposing effect and are printed in bold. $\mathrm{ACPA}=$ anti-citrullinated protein antibody; $\mathrm{RA}=$ rheumatoid arthritis; $95 \% \mathrm{CI}=95 \%$ confidence interval. 
Table 3. HLA-DRB1 associations with ACPA-positive RA according to meta-analysis*.

\begin{tabular}{|c|c|c|}
\hline HLA-DRB1 allele & OR $(95 \% \mathrm{CI})$ & $\mathrm{P}$ \\
\hline${ }^{\star} 01$ & $1.38(1.25-1.53)$ & $<0.001$ \\
\hline European Populations & $1.34(1.20-1.51)$ & $<0.001$ \\
\hline Non-European Populations & $1.52(1.20-1.92)$ & $<0.001$ \\
\hline${ }^{\star} 03$ & $0.61(0.52-0.71)$ & $<0.001$ \\
\hline European Populations & $0.60(0.51-0.70)$ & $<0.001$ \\
\hline Non-European Populations & $0.68(0.45-1.05)$ & 0.08 \\
\hline${ }^{\star} 04$ & $2.31(1.89-2.83)$ & $<0.001$ \\
\hline European Populations & $2.51(2.09-3.01)$ & $<0.001$ \\
\hline Non-European Populations & $1.98(1.37-2.85)$ & $<0.001$ \\
\hline${ }^{\star} 0401$ & $2.85(2.50-3.24)$ & $<0.001$ \\
\hline European Populations & $2.80(2.46-3.20)$ & $<0.001$ \\
\hline Non-European Populations & $3.33(1.97-5.63)$ & $<0.001$ \\
\hline${ }^{\star} 0402$ & $0.93(0.31-2.77)$ & 0.89 \\
\hline *0403 & $0.57(0.36-0.91)$ & 0.02 \\
\hline${ }^{*} 0404$ & $2.37(1.96-2.86)$ & $<0.001$ \\
\hline${ }^{*} 0405$ & $2.62(1.86-3.70)$ & $<0.001$ \\
\hline European Populations & $2.98(1.58-5.60)$ & 0.001 \\
\hline Non-European Populations & $2.25(1.95-2.58)$ & $<0.001$ \\
\hline${ }^{*} 0406$ & $0.46(0.31-0.70)$ & $<0.001$ \\
\hline${ }^{*} 0407$ & $0.37(0.11-1.25)$ & 0.11 \\
\hline${ }^{*} 0408$ & $3.70(0.48-28.56)$ & 0.21 \\
\hline${ }^{\star} 07$ & $0.65(0.58-0.74)$ & $<0.001$ \\
\hline European Populations & $0.67(0.58-0.76)$ & $<0.001$ \\
\hline Non-European Populations & $0.50(0.31-0.82)$ & 0.005 \\
\hline${ }^{\star} 08$ & $0.54(0.34-0.87)$ & 0.01 \\
\hline European Populations & $0.65(0.27-1.55)$ & 0.33 \\
\hline Non-European Populations & $0.50(0.40-0.61)$ & $<0.001$ \\
\hline${ }^{*} 09$ & $1.53(0.98-2.38)$ & 0.06 \\
\hline European Populations & $2.05(1.08-3.87)$ & 0.03 \\
\hline Non-European Populations & $1.21(0.69-2.11)$ & 0.51 \\
\hline${ }^{*} 10$ & $2.30(1.66-3.18)$ & $<0.001$ \\
\hline European Populations & $2.31(1.72-3.09)$ & $<0.001$ \\
\hline Non-European Populations & $3.13(0.97-10.14)$ & 0.06 \\
\hline${ }^{*} 11$ & $0.62(0.55-0.70)$ & $<0.001$ \\
\hline European Populations & $0.62(0.54-0.70)$ & $<0.001$ \\
\hline
\end{tabular}




\section{Continuous}

\begin{tabular}{|c|c|c|}
\hline Non-European Populations & $0.63(0.43-0.91)$ & 0.01 \\
\hline${ }^{\star} 12$ & $0.72(0.57-0.91)$ & 0.01 \\
\hline European Populations & $0.62(0.42-0.91)$ & 0.02 \\
\hline Non-European Populations & $0.80(0.60-1.07)$ & 0.13 \\
\hline${ }^{\star} 13$ & $0.50(0.41-0.62)$ & $<0.001$ \\
\hline European Populations & $0.50(0.37-0.67)$ & $<0.001$ \\
\hline Non-European Populations & $0.47(0.37-0.61)$ & $<0.001$ \\
\hline *1301 & $0.20(0.10-0.38)$ & $<0.001$ \\
\hline${ }^{\star} 1302$ & $0.45(0.35-0.59)$ & $<0.001$ \\
\hline${ }^{\star} 14$ & $0.63(0.53-0.75)$ & $<0.001$ \\
\hline European Populations & $0.58(0.44-0.76)$ & $<0.001$ \\
\hline Non-European Populations & $0.67(0.54-0.84)$ & $<0.001$ \\
\hline${ }^{\star} 1402$ & $0.37(0.08-1.65)$ & 0.19 \\
\hline${ }^{\star} 15$ & $0.84(0.76-0.92)$ & $<0.001$ \\
\hline European Populations & $0.85(0.75-0.97)$ & 0.02 \\
\hline Non-European Populations & $0.90(0.64-1.26)$ & 0.54 \\
\hline${ }^{\star} 16$ & $1.16(0.94-1.43)$ & 0.17 \\
\hline European Populations & $1.25(0.99-1.56)$ & 0.06 \\
\hline Non-European Populations & $0.74(0.40-1.36)$ & 0.33 \\
\hline
\end{tabular}

${ }^{*}$ Odds ratios (ORs) depicting a negative association with a $\mathrm{P}$ value of $<0.01$ after stratification were considered to represent a protective effect and are printed in bold; ORs depicting a positive association with a $\mathrm{P}$ value of $<0.01$ after stratification were considered to represent a predisposing effect and are printed in bold. ACPA = anti-itrullinated protein antibody; $\mathrm{RA}=$ rheumatoid arthritis; $95 \% \mathrm{CI}=95 \%$ confidence interval.

$\mathrm{DRB}^{\star}{ }^{*} 404, \mathrm{DRB} 1^{\star} 0406, \mathrm{DRB} 1^{\star} 1301$ and $\mathrm{DRB} 1^{\star} 1302$ were associated with ACPApositive RA was possibly hampered due to relatively small numbers of patients and control groups.

Because the results may vary based on geographical differences, the subgroup was performed between European populations and Asia or/and African populations. It has been also confirmed that the hierarchy in the strength of this association was DRB1 ${ }^{\star} 04>\mathrm{DRB} 1{ }^{\star} 10>\mathrm{DRB} 1{ }^{\star} 01$ in our meta-analysis in European ACPA-positive RA patients. We observed that the protective effects of HLA-DRB1 ${ }^{\star} 07,{ }^{\star} 11,{ }^{\star} 13$ and ${ }^{\star} 14$ and the predisposing effects of HLA-DRB $1{ }^{\star} 01,{ }^{\star} 04,{ }^{\star} 0401,{ }^{\star} 0405$ did not appear to be restricted in geographical differences. However, the protective effects of HLA-DRB1 ${ }^{\star} 10$ and the predisposing effects of HLA-DRB1 ${ }^{\star} 03$ and ${ }^{\star} 12$ were limited to European populations.

\subsection{Associations between HLA-DRB1*07 and ACPA-Positive or ACPA-Negative RA}

The data showed the $\mathrm{DRB} 1{ }^{\star} 07$ carried protective effect in ACPA-negative RA (OR 0.54 
[95\% CI 0.39 - 0.75]) and ACPA-positive RA (OR 0.65 [95\% CI 0.58 - 0.74]) based on data of none-classification in geographical differences (Figure 2(a) and Figure 2(b)). Though the DRB ${ }^{\star} 07$ showed protective effect (OR 0.52 [95\% CI 0.36-0.75]) of ACPAnegative RA in European populations, there is no association (OR 0.65 [95\% CI 0.31 1.35]) with ACPA-negative RA in Asia or/and African populations (Figure 2(c) and Figure 2(d)). These results indicated the strong correlation of DRB1*07 with ACPAnegative RA in European populations. Concomitantly, in the ACPA-positive patients, the $\mathrm{DRB} 1^{\star} 07$ provided the protective correlation with ACPA-positive RA in European populations (OR 0.67 [95\% CI 0.58 - 0.76]) and Asia or/and African populations (OR 0.50 [95\% CI $0.31-0.82]$ ) (Figure 2(e) and Figure 2(f)). We therefore concluded that regardless the ACPA positive or negative, the $\mathrm{DRB} 1^{\star} 07$ was always associated with protection in European populations.

\subsection{Sensitivity Analysis and Publication Bias}

The sensitivity analysis indicated that each study was sequentially removed and the results were consistent. No significant publication bias was shown in the funnel plots. What's more, no significant evidence for publication bias was revealed by the regression asymmetry test.

\section{Discussion}

There have been difficulties for dissecting the effects of the various HLA alleles to RA susceptibility due to polymorphic HLA alleles. Many authorities have tried to clarify the predisposing and protective effects of the HLA alleles for RA. Several studies indicated that the ACPA-status and geographic distribution were essential factors which affected the effects of the HLA alleles on RA [28] [29]. Previous studies also have shown that the effects of the various subtypes in RA susceptibility were discordant indifferent regions and nationalities [13]; thus the stratification by geographical differences was performed in our meta-analysis. Additionally, our data not only document the association of HLA-DRB1 alleles with influence but also considerably refine the definition of predisposing and protective alleles.

Our present study shows that the HLA-DRB1 ${ }^{\star} 01,{ }^{\star} 04,{ }^{\star} 0401,{ }^{\star} 0405$ play predisposing roles in the correlation with ACPA-positive RA whereas the HLA-DRB1* $11,{ }^{\star} 13$ and ${ }^{\star} 14$ are associated with ACPA-positive protection regardless of European populations or Asia or/and African populations. These results are in accordance with studies performed by Diane van der Woude [6] and Kyung Ran Jun [30]. Previous study has shown that the predisposing effect of HLA-DRB1 ${ }^{*} 0401$ was the most frequent allele in white population and Jew [31], whereas the HLA-DRB1 ${ }^{\star} 0405$ was a rare allele in European population [32]. Additionally, we found that the HLA-DRB ${ }^{\star} 0405$ may provide protection in ACPA-negative RA in the study, but further studies are necessary to confirm this association. Our results show that the protective effects of HLA-DRB1* 13 with ACPA-positive RA in European populations is commonly present. These results are also consistent with studies performed by Diane van der Woude [6]. Furthermore, Data 


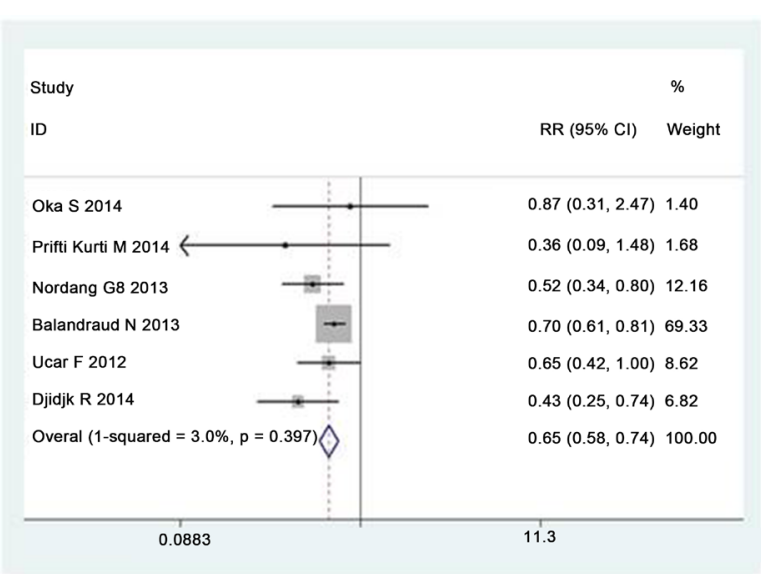

(a)

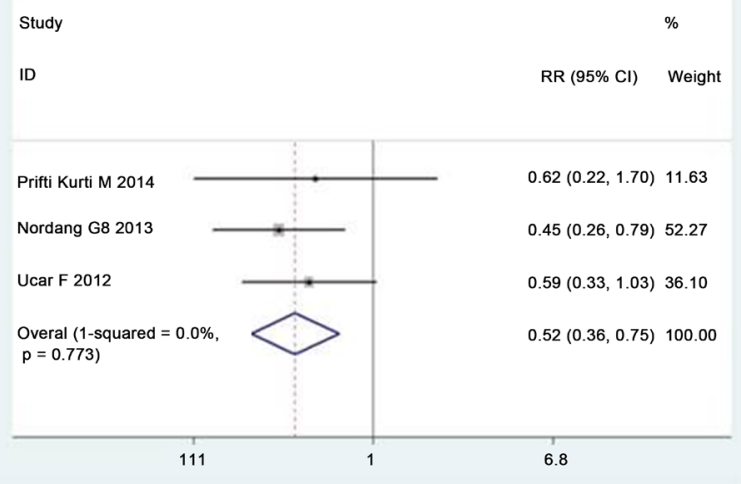

(c)

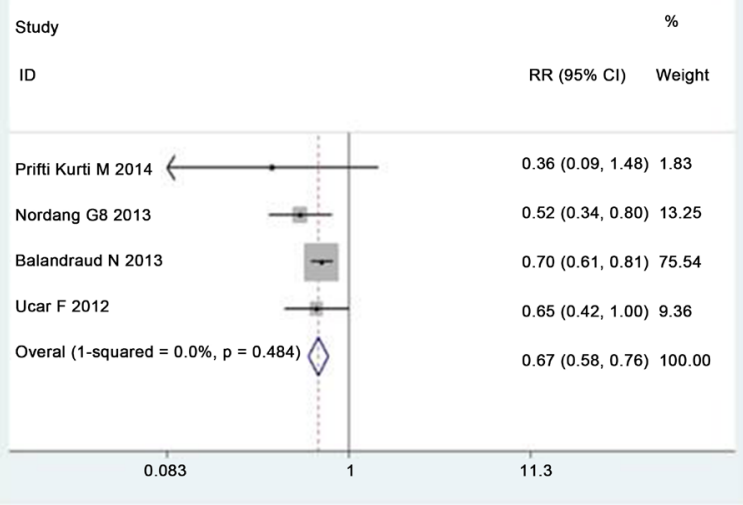

(e)

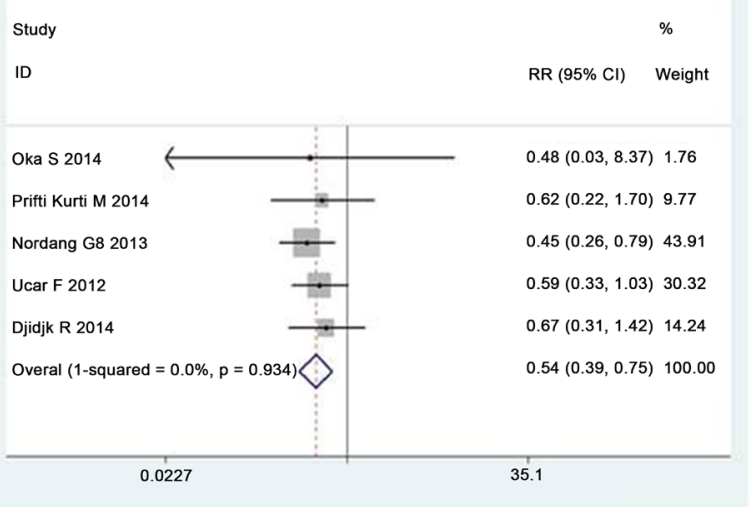

(b)

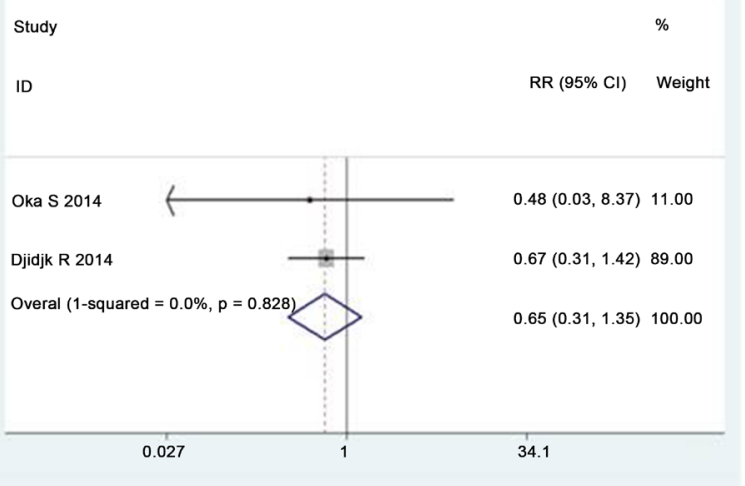

(d)

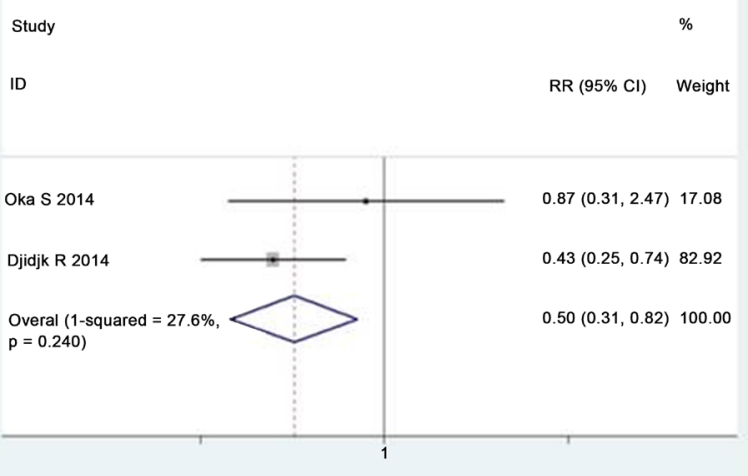

(f)

Figure 2. Effect of DRB1 ${ }^{\star} 07$ in ACPA-positive and ACPA-negative rheumatoid arthritis. Forest plots depict the ORs and $95 \%$ confidence intervals in ACPA-positive or negative RA populations with typing of the DRB1 ${ }^{\star} 07$ alleles. (a) Effect of $\mathrm{DRB} 1{ }^{\star} 07$ in the ACPA-positive RA populations without stratification by geographical differences. (b) Effect of DRB1 07 in the ACPA-negative RA populations without stratification by geographical differences. (c) Effect of $D R B 1 * 07$ in the ACPA-negative RA European populations. (d) Effect of DRB1 ${ }^{\star} 07$ in the ACPA-negative RA Non-European populations. (e) Effect of DRB1 ${ }^{\star} 07$ in the ACPA-positive RA European populations. (f) Effect of DRB1*07 in the ACPA-positive RAN on-European populations. 
from Table 2 and Table 3 suggest that protective to ACPA-negative RA by the DRB $1^{\star} 13$ alleles is apparent only from $\mathrm{DRB} 1^{\star} 1301$. Although the protective effects was weak, the possibility that $\mathrm{DRB} 1^{\star} 1301$ was protective association with ACPA-negative RA should not be exclude. However, the $\mathrm{DRB}^{\star} 13$ alleles affording protection in ACPA-positive RA is linked both to the $\mathrm{DRB} 1^{\star} 1301$ and $\mathrm{DRB} 1^{\star} 1302$. Obviously, the protective effect need to be confirmed in different populations and larger numbers of patients.

It is clear from table 3 that the protective effects of HLA-DRB ${ }^{\star} 10$ and the predisposing effects of HLA-DRB $1^{\star} 03$ and ${ }^{\star} 12$ are observed in ACPA-positive RA European populations, but not in ACPA-positive RAN on-European populations. It suggests that these associations may be only present in ACPA-positive RA European populations. However, the effects of HLA-DRB $1{ }^{\star} 03,{ }^{\star} 10$ and ${ }^{\star} 12$ were not observed in ACPA-positive RA European populations. Further investigation indicated that the predisposing effects of HLA-DRB $1^{\star} 10$ and ${ }^{\star} 12$ were found in ACPA-negative RA Non-European populations. These results need to be clarified due to small sample size.

In addition, as can be seen from Figure 2(b), Figure 2(c), and Figure 2(d), for the ACPA- negative RA patients, the protective effect of $\mathrm{HLA}-\mathrm{DRB} 1^{\star} 07$ is apparent only in European populations. However, for the ACPA-positive RA patients, HLA-DRB $1^{\star} 07$ afforded protective function without geographical difference (Figure 2(a), Figure 2(e) and Figure 2(f). Therefore, our analysis of the $\mathrm{DRB} 1^{\star} 07$ alleles indicated that the protection were present both for ACPA-positive RA and ACPA-negative RA in European populations. Although the study about the HLA-DRB1 alleles for the ACPA-positive RA patients included $>13,000$ patients and $>12,000$ control subjects from different populations, the possibility as $\mathrm{HLA}-\mathrm{DRB} 1^{\star} 07$ that protections are also present for other HLA-DRB1 alleles not observed in the present study.

Concomitantly, we can't ignore several limitations in our analysis. For example, first, the publication bias can't be excluded, because the cases used are case-control study rather than prospective randomized controlled studies [33] [34]. Secondly, we distinguish the geographical populations into European Populations and Non-European Populations, and the date from Asian and African populations grouped together as Non-European Populations in the analysis. However this group method may result in false-positive results. Thirdly, not all polymorphism, for example shared epitope (SE) and smoking, were analyzed in subgroups due to the limited number of articles included. However, several studies have indicated that shared epitope (SE) and smoking were strongly associated with RA [35] [36]. Fourthly, heterozygosity effects for the various other HLA-DRB1 alleles were not investigated separately. Fifth, the non-consideration of several potential factors of influential environments may influence the results. Sixth, our search was only conducted in English journals. However, even with several limitations, we feel our analysis was with adequate methodological quality and the results were reliable.

\section{Conclusion}

Overall, our study shows that in ACPA-positive RA, current available results indicate 
that the HLA-DRB ${ }^{\star} 01,{ }^{\star} 04,{ }^{\star} 0401$ and ${ }^{*} 0405$ are susceptible, while the HLA-DRB1 ${ }^{\star} 07,{ }^{\star} 11,{ }^{\star} 13$ and ${ }^{\star} 14$ are protective in all populations. In addition, it was found that HLA-DRB $1^{\star} 10$ was susceptible, and HLA-DRB $1^{\star} 03$ and ${ }^{\star} 12$ showed protective association with RA in European populations. Furthermore, regardless of the positive or negative $\mathrm{ACPA}$, the $\mathrm{DRB} 1^{\star} 07$ is always associated with protection in European populations.

\section{Authors' Contributions}

WG, QL, HF and Yan J. designed experiments. HF, JX, NZ, LW, TG and CT analyzed data. QL, HF and WG conceived and managed the project. HF, JX, LW, KH and WG contributed to manuscript preparation. All authors contribute to manuscript finalization.

\section{Conflict of Interest}

The authors declare that there are no conflicts of interest.

\section{Acknowledgements}

This work was partially supported by the Center of Genomics and Bioinformatics and Center of Connective Tissue Research at the University of Tennessee Health Science Center; The department of technology in Hebei province, PR China (to QL).

\section{References}

[1] Picerno, V., Ferro, F., Adinolfi, A., Valentini, E., Tani, C. and Alunno, A. (2015) One Year in Review: The Pathogenesis of Rheumatoid Arthritis. Clinical and Experimental Rheumatology, 33, 551-558.

[2] Wu, M., Li, Y. and Zhang, P. (2015) Pathophysiologic Mechanisms and Risk Management of Cardiovascular Disease in Patients with Rheumatoid Arthritis. Zhonghua Xin Xue Guan Bing Za Zhi, 43, 374-376.

[3] Viatte, S., Plant, D., Han, B., Fu, B., Yarwood, A., et al. (2015) Association of HLA-DRB1 Haplotypes with Rheumatoid Arthritis Severity, Mortality, and Treatment Response. JAMA, 313, 1645-1656. https://doi.org/10.1001/jama.2015.3435

[4] Furukawa, H., Oka, S., Shimada, K., Hashimoto, A. and Tohma, S. (2015) Human Leukocyte Antigen Polymorphisms and Personalized Medicine for Rheumatoid Arthritis. Journal of Human Genetics, 60, 691-696. https:/doi.org/10.1038/jhg.2015.36

[5] Balandraud, N., Picard, C., Reviron, D., Landais, C., Toussirot, E., et al. (2013) HLA-DRB1 Genotypes and the Risk of Developing Anti Citrullinated Protein Antibody (ACPA) Positive Rheumatoid Arthritis. PLoS ONE, 8, e64108.

https://doi.org/10.1371/journal.pone.0064108

[6] van der Woude, D., Lie, B.A., Lundstrom, E., Balsa, A., Feitsma, A.L., et al. (2010) Protection against Anti-Citrullinated Protein Antibody-Positive Rheumatoid Arthritis Is Predominantly Associated with HLA-DRB1*1301: A Meta-Analysis of HLA-DRB1 Associations with Anti-Citrullinated Protein Antibody-Positive and Anti-Citrullinated Protein Antibody-Negative Rheumatoid Arthritis in Four European Populations. Arthritis \& Rheumatology, 62, 1236-1245. https://doi.org/10.1002/art.27366

[7] Ronninger, M., Seddighzadeh, M., Eike, M.C., Plant, D., Daha, N.A., et al. (2012) Interac- 
tion Analysis between HLA-DRB1 Shared Epitope Alleles and MHC Class II Transactivator CIITA Gene with Regard to Risk of Rheumatoid Arthritis. PLoS ONE, 7, e32861. https://doi.org/10.1371/journal.pone.0032861

[8] Morgan, A.W., Haroon-Rashid, L., Martin, S.G., Gooi, H.C., Worthington, J., et al. (2008) The Shared Epitope Hypothesis in Rheumatoid Arthritis: Evaluation of Alternative Classification Criteria in a Large UK Caucasian Cohort. Arthritis \& Rheumatology, 58, 1275 1283. https://doi.org/10.1002/art.23432

[9] Djidjik, R., Allam, I., Douaoui, S., Meddour, Y., Cherguelaine, K., Tahiat, A., et al. (2014) Association Study of Human Leukocyte Antigen-DRB1 Alleles with Rheumatoid Arthritis in Algerian Patients. International Journal of Rheumatic Diseases. https:/doi.org/10.1111/1756-185X.12272

[10] de Vries, R.R., van der Woude, D., Houwing, J.J. and Toes, R.E. (2011) Genetics of ACPAPositive Rheumatoid Arthritis: The Beginning of the End. Annals of the Rheumatic Diseases, 70, i51-i54. https://doi.org/10.1136/ard.2010.138040

[11] Oka, S., Furukawa, H., Kawasaki, A., Shimada, K., Sugii, S., et al. (2014) Protective Effect of the HLA-DRB1*13:02 Allele in Japanese Rheumatoid Arthritis Patients. PLoS ONE, 9, e99453. https:/doi.org/10.1371/journal.pone.0099453

[12] Kim, K., Bang, S.Y., Yoo, D.H., Cho, S.K., Choi, C.B., Sung, Y.K., Kim, T.H., Jun, J.B., Kang, Y.M., Suh, C.H., Shim, S.C., Lee, S.S., Lee, J., Chung, W.T., Kim, S.K., Choe, J.Y., Nath, S.K., Lee, H.S. and Bae, S.C. (2016) Imputing Variants in HLA-DR Beta Genes Reveals That HLA-DRB1 Is Solely Associated with Rheumatoid Arthritis and Systemic Lupus Erythematosus. PLOS ONE, 11, e0150283.

[13] Yang, M., Kuang, X., Li, J., Pan, Y., Tan, M., Lu, B., et al. (2013) Meta-Analysis of the Association of HLA-DRB1 with Rheumatoid Arthritis in Chinese Populations. BMC Musculoskeletal Disorders, 14. https:/doi.org/10.1186/1471-2474-14-307

[14] Stang, A. (2010) Critical Evaluation of the Newcastle-Ottawa Scale for the Assessment of the Quality of Nonrandomized Studies in Meta-Analyses. European Journal of Epidemiology, 25, 603-605. https:/doi.org/10.1007/s10654-010-9491-Z

[15] Lucenteforte, E., Moja, L., Pecoraro, V., Conti, A.A., Conti, A., Conti, A., et al. (2015) Discordances Originated by Multiple Meta-Analyses on Interventions for Myocardial Infarction: A Systematic Review. Journal of Clinical Epidemiology, 68, 246-256.

https:/doi.org/10.1016/j.jclinepi.2014.11.004

[16] Farina, E., Raglio, A. and Giovagnoli, A.R. (2015) Cognitive Rehabilitation in Epilepsy: An Evidence-Based Review. Epilepsy Research, 109, 210-218. https:/doi.org/10.1016/j.eplepsyres.2014.10.017

[17] Singh, S. and Khosla, S. (2015) Suboptimal Choice of Methodology for Meta-Analysis and Publication Bias Assessment. The American Journal of Cardiology, 115, 1782-1783. https:/doi.org/10.1016/j.amjcard.2015.04.001

[18] Prifti-Kurti, M., Nunes, J.M., Shyti, E., Ylli, Z., Sanchez-Mazas, A. and Sulcebe, G. (2014) HLA-DRB1 and HLA-DQB1 Allele Associations in an Albanian Patient Population with Rheumatoid Arthritis: Correlations with the Specific Autoantibody Markers and InterPopulation DRB1 Allele Frequency Variability. Rheumatology International, 34, 1065-1071. https:/doi.org/10.1007/s00296-013-2932-8

[19] Nordang, G.B., Flam, S.T., Maehlen, M.T., Kvien, T.K., Viken, M.K. and Lie, B.A. (2013) HLA-C Alleles Confer Risk for Anti-Citrullinated Peptide Antibody-Positive Rheumatoid Arthritis Independent of HLA-DRB1 Alleles. Rheumatology (Oxford), 52, 1973-1982.

[20] Ucar, F., Capkin, E., Karkucak, M., Yucel, B., Sonmez, M., Alver, A., et al. (2012) Associa- 
tions of HLA-DRB1 Alleles with Anti-Citrullinated Protein Antibody-Positive and AntiCitrullinated Protein Antibody-Negative Rheumatoid Arthritis in Northern East Part of Turkey. International Journal of Rheumatic Diseases, 15, 538-545. https:/doi.org/10.1111/j.1756-185X.2011.01604.x

[21] Too, C.L., Yahya, A., Murad, S., Dhaliwal, J.S., Larsson, P.T., Muhamad, N.A., et al. (2012) Smoking Interacts with HLA-DRB1 Shared Epitope in the Development of Anti-Citrullinated Protein Antibody-Positive Rheumatoid Arthritis: Results from the Malaysian Epidemiological Investigation of Rheumatoid Arthritis (MyEIRA). Arthritis Research \& Therapy, 14, R89. https:/doi.org/10.1186/ar3813

[22] Ben, H.M., Mahfoudh, N., Marzouk, S., Kammoun, A., Gaddour, L., Hakim, F., et al. (2012) Association Study of Human Leukocyte Antigen-DRB1 Alleles with Rheumatoid Arthritis in South Tunisian Patients. Clinical Rheumatology, 31, 937-942. https:/doi.org/10.1007/s10067-012-1954-z

[23] Mackie, S.L., Taylor, J.C., Martin, S.G., Wordsworth, P., Steer, S., Wilson, A.G., et al. (2012) A Spectrum of Susceptibility to Rheumatoid Arthritis within HLA-DRB1: Stratification by Autoantibody Status in a Large UK Population. Genes and Immunity, 13, 120-128. https:/doi.org/10.1038/gene.2011.60

[24] Terao, C., Ohmura, K., Kochi, Y., Ikari, K., Maruya, E., Katayama, M., et al. (2011) A Large-Scale Association Study Identified Multiple HLA-DRB1 Alleles Associated with ACPA-Negative Rheumatoid Arthritis in Japanese Subjects. Annals of the Rheumatic, Diseases, 70, 2134-2139. https:/doi.org/10.1136/annrheumdis-2011-200353

[25] Ding, B., Padyukov, L., Lundstrom, E., Seielstad, M., Plenge, R.M., Oksenberg, J.R., et al. (2009) Different Patterns of Associations with Anti-Citrullinated Protein Antibody-Positive and Anti-Citrullinated Protein Antibody-Negative Rheumatoid Arthritis in the Extended Major Histocompatibility Complex Region. Arthritis \& Rheumatology, 60, 30-38. https:/doi.org/10.1002/art.24135

[26] Van Beers, J.J., Willemze, A., Stammen-Vogelzangs, J., Drijfhout, J.W., Toes, R.E. and Pruijn, G.J. (2012) Anti-Citrullinated Fibronectin Antibodies in Rheumatoid Arthritis Are Associated with Human Leukocyte Antigen-DRB1 Shared Epitope Alleles. Arthritis Research \& Therapy, 14, R35.

[27] Shimane, K., Kochi, Y., Suzuki, A., Okada, Y., Ishii, T., et al. (2013) An Association Analysis of HLA-DRB1 with Systemic Lupus Erythematosus and Rheumatoid Arthritis in a Japanese Population: Effects of ${ }^{\star}$ 09:01 Allele on Disease Phenotypes. Rheumatology $($ Oxford $)$, 52, 1172-1182. https:/doi.org/10.1093/rheumatology/kes427

[28] Jiang, X., Trouw, L., Van Wesemael, T., Shi, J., Bengtsson, C., et al. (2014) Anti-CarP Antibodies in Two Large Cohorts of Patients with Rheumatoid Arthritis and Their Relationship to Genetic Risk Factors, Cigarette Smoking and Other Autoantibodies. Annals of the Rheumatic Diseases, 73, 1761-1768.

[29] Maehlen, M.T., Olsen, I.C., Andreassen, B.K., Viken, M.K., Jiang, X., et al. (2015) Genetic Risk Scores and Number of Autoantibodies in Patients with Rheumatoid Arthritis. Annals of the Rheumatic Diseases, 74, 762-768.

[30] Jun, K.R., Choi, S.E., Cha, C.H., Oh, H.B., Heo, Y.S., Ahn, H.Y., et al. (2007) Meta-Analysis of the Association between HLA-DRB1 Allele and Rheumatoid Arthritis Susceptibility in Asian Populations. Journal of Korean Medical Science, 22, 973-980. https:/doi.org/10.3346/jkms.2007.22.6.973

[31] Zanelli, E., Breedveld, F.C. and de Vries, R.R. (2000) HLa Class II Association with Rheumatoid Arthritis: Facts and Interpretations. Human Immunology, 61, 1254-1261. https:/doi.org/10.1016/S0198-8859(00)00185-3 
[32] Terao, C., Yano, K., Ikari, K., Furu, M., Yamakawa, N., Yoshida, S., et al. (2015) Brief Report: Main Contribution of DRB1*04:05 among the Shared Epitope Alleles and Involvement of DRB1 Amino Acid Position 57 in Association with Joint Destruction in Anti-Citrullinated Protein Antibody-Positive Rheumatoid Arthritis. Arthritis \& Rheumatology, 67, 1744-1750. https:/doi.org/10.1002/art.39105

[33] Rouch, L., Cestac, P., Hanon, O., Cool, C., Helmer, C., Bouhanick, B., et al. (2015) Antihypertensive Drugs, Prevention of Cognitive Decline and Dementia: A Systematic Review of Observational Studies, Randomized Controlled Trials and Meta-Analyses, with Discussion of Potential Mechanisms. CNS Drugs, 29, 113-130.

https:/doi.org/10.1007/s40263-015-0230-6

[34] Mak, A., Cheung, M.W., Ho, R.C., Cheak, A.A. and Lau, C.S. (2009) Bisphosphonates and Atrial Fibrillation: Bayesian Meta-Analyses of Randomized Controlled Trials and Observational Studies. BMC Musculoskeletal Disorders, 10, 113.

https:/doi.org/10.1186/1471-2474-10-113

[35] Lundstrom, E., Kallberg, H., Alfredsson, L., Klareskog, L. and Padyukov, L. (2009) GeneEnvironment Interaction between the DRB1 Shared Epitope and Smoking in the Risk of Anti-Citrullinated Protein Antibody-Positive Rheumatoid Arthritis: All Alleles Are Important. Arthritis \& Rheumatology, 60, 1597-1603. https:/doi.org/10.1002/art.24572

[36] Balsa, A., Cabezon, A., Orozco, G., Cobo, T., Miranda-Carus, E., López-Nevot, M.Á., et al. (2010) Influence of HLA DRB1 Alleles in the Susceptibility of Rheumatoid Arthritis and the Regulation of Antibodies against Citrullinated Proteins and Rheumatoid Factor. Arthritis Research \& Therapy, 12, R62. https:/doi.org/10.1186/ar2975

Submit or recommend next manuscript to SCIRP and we will provide best service for you:

Accepting pre-submission inquiries through Email, Facebook, LinkedIn, Twitter, etc.

A wide selection of journals (inclusive of 9 subjects, more than 200 journals)

Providing 24-hour high-quality service

User-friendly online submission system

Fair and swift peer-review system

Efficient typesetting and proofreading procedure

Display of the result of downloads and visits, as well as the number of cited articles

Maximum dissemination of your research work

Submit your manuscript at: http://papersubmission.scirp.org/

Or contact oji@scirp.org 